\title{
Formation of Boron Enolates by Nucleophilic Substitution
}

\author{
George R. A. Garratt \\ Graham Pattison*a \\ ${ }^{a}$ Chemistry Research Group, School of Pharmacy and \\ Biomolecular Science, Huxley Building, Lewes Road, Brighton, \\ BN2 4GJ. United Kingdom \\ g.pattison@brighton.ac.uk
}

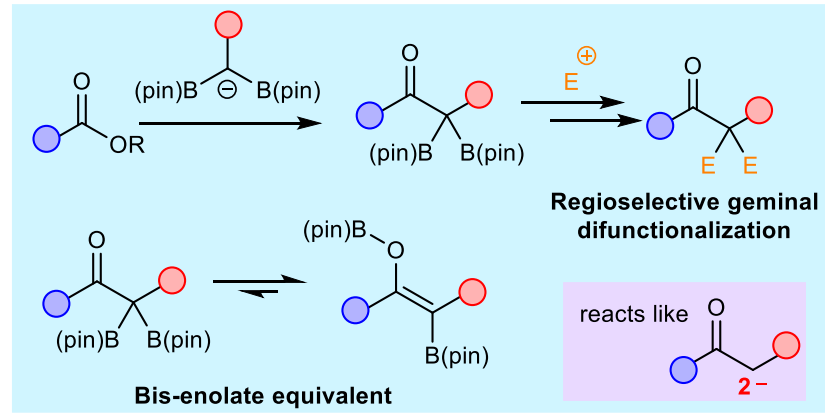

\begin{abstract}
Received: Published online:

DO

Abstract Enolates have proven to be one of the key building blocks available to the synthetic chemist. Here we summarize a novel strategy for their preparation, involving the addition of $\alpha$-borylated nucleophiles to esters to yield boron enolates. The enolates prepared by the addition of lithiated geminal bis(boron) compounds to esters can be trapped with two equivalents of halogen and alkyl electrophiles to yield $\alpha, \alpha$-difunctionalized compounds.

Key words Enolates; Coupling; Boron; Fluorination
\end{abstract}

\section{Introduction}

The enolate has been one of the mainstay building-blocks of organic synthesis for over 150 years. ${ }^{1}$ Undergraduate students are taught at an early stage of their courses that we can prepare enolates by deprotonation adjacent to a carbonyl group.

Enolate formation by deprotonation does raise some difficulties, particularly with regard to regioselectivity. If a ketone is nonsymmetrical, and deprotonation is possible at either $\alpha$-position, then at which side of the ketone will enolate formation occur? The classical method to overcome this challenge is through using either kinetic or thermodynamic control of enolate formation; ${ }^{2}$ under equilibrating conditions the more substituted thermodynamic enolate is formed, and under low temperature conditions with a hindered base then a kinetic enolate is formed at the least substituted position. However, in many cases achieving complete control using this method may be difficult and in cases where both sides of a ketone are similar (e.g. both are secondary carbons) then it may not be obvious which enolate is more stable.

At the outset of this project we wondered whether it might be possible to form enolate-like intermediates in a different way. Could we form an intermediate with enolate-like reactivity by performing a nucleophilic substitution of an ester with an $\alpha$ borylated nucleophile (Scheme 1)? This would introduce a boron atom at a carbon atom adjacent to a carbonyl group (i.e. a boron enolate). Such boron enolates typically undergo a rapid tautomerization of boron from carbon to oxygen to form an 0bound boron enolate (although $\mathrm{C}$-bound boron enolates are known). ${ }^{3}$ The strength of a $\mathrm{B}-\mathrm{O}$ bond is significantly higher than that of a B-C bond which facilitates this tautomerization. We hoped that this approach would provide a regioselective and predictable strategy for enolate formation, without the need for selective deprotonation events.

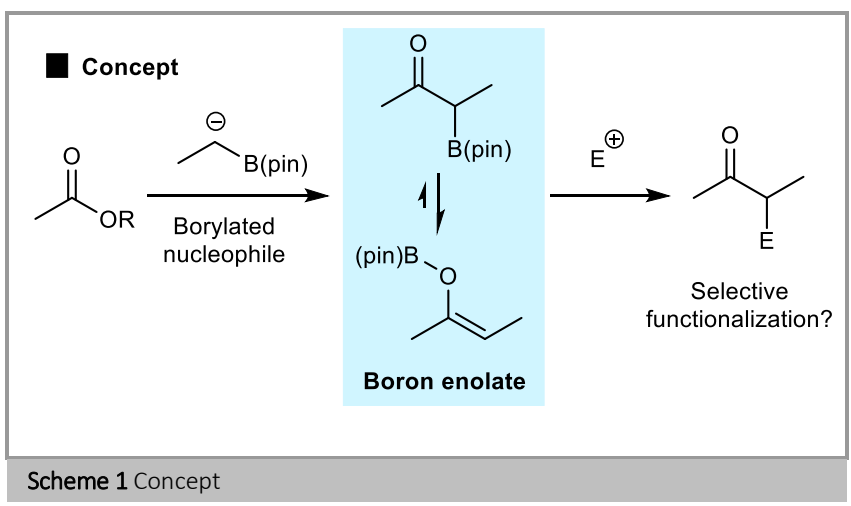

This approach has some precedent from the work of Matteson and Mukaiyama in the 1980s (Scheme 2). Matteson demonstrated that $\alpha$-borylated anions could undergo addition to esters, ${ }^{4}$ followed by protonation to yield a ketone, whilst Mukaiyama extended this to show that boron enolates generated by this method could undergo aldol reactions with aldehydes. ${ }^{5}$ This was all an extension of boron-Wittig chemistry developed in particular by the Matteson group, ${ }^{6}$ involving the addition of $\alpha$-borylated anions derived from geminal bis(boron) compounds to aldehydes and ketones to yield vinyl boronates. The author's laboratory has also been active in this area, using a boron-Wittig / oxidation sequence to develop a homologative coupling of aldehydes and ketones with geminal bis(boron) compounds, a reaction which both extends a carbon chain containing a carbonyl group by one carbon whilst simultaneously introducing a new ketone substituent.7 
Previous Results

Matteson<smiles>COC(=O)c1ccccc1</smiles><smiles>CCCCCCCC([AlH2])(B1OCCCO1)B1OCCCO1</smiles><smiles>CCCC</smiles><smiles>O=C(c1ccccc1)c1ccccc1</smiles>
$99 \%$

Anion formation by deprotonation

Boron-Wittig - Matteson / Endo / Shibata / Morken

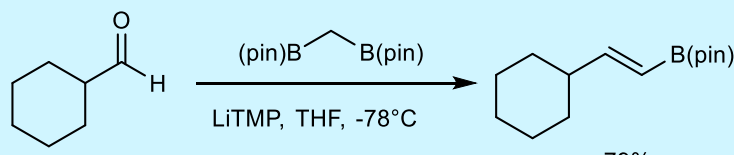

$79 \%$

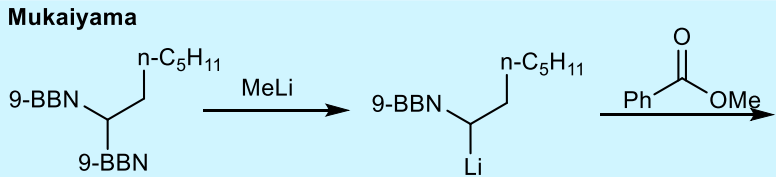

Anion formation by deborylation<smiles>CCCCCCCCCCOC(O[GaH2])c1ccccc1</smiles>
-BBN

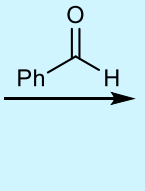

$\overbrace{\mathrm{n}-\mathrm{C}_{5} \mathrm{H}_{11}}^{\mathrm{OH}}$

Overall yield $=80 \%$ $\mathrm{dr}=16: 84$

Scheme 2 Previous results in the addition of borylated anions to carbonyl compounds

All of this precedent boded well for the development of novel enolate formation and trapping processes triggered by the addition of $\alpha$-borylated nucleophiles to esters. However, the regiospecificity of such processes was unstudied previously to our work - would electrophilic trapping always take place selectively at the position that boron was introduced?

\section{Ketone difunctionalization}

A particular challenge in enolate chemistry that we felt this approach could solve is that of difunctionalization. In certain circumstances synthetic chemists may wish to introduce two substituents on the same side of a carbonyl group through sequential enolate formation/ electrophilic trapping processes (Scheme 3). However, in many cases this approach does not result in a desired $\alpha, \alpha$-difunctionalization product, instead yielding a mixture of products due to non-selective enolate formation. The first substituent introduced likely influences the site of formation of the second enolate.

Probably the best known current approach for $\alpha, \alpha$ difunctionalization adjacent to a carbonyl group would involve the use of an $\alpha$-diazocarbonyl compound (Scheme 3). ${ }^{8}$ These are versatile building blocks, which in terms of a synthon approach, react as if they have both a negative and positive charge on the $\alpha$ carbon. This reactivity profile can make it difficult to introduce two identical groups adjacent to a carbonyl group. We considered that an alternative synthon, with two negative charges on the $\alpha$ carbon could be a better conceptual approach if the introduction of two identical groups was required. However, access to such a dianionic synthon had seen little progress towards its development. ${ }^{9}$

Our approach was to use geminal bis(boron) compounds ${ }^{10}$ as equivalents of dianions (Scheme 3). ${ }^{11}$ A geminal bis(boron) compound is relatively acidic at the site between the boron atoms due to stabilization of the formed anion by the vacant boron porbitals. Choice of base is very important to achieve successful deprotonation at this position. Small, nucleophilic Lewis bases such as $\mathrm{KO}$ tBu and MeLi attack boron directly and lead to deboronation and the formation of an $\alpha$-mono(boryl) carbanion. The use of more sterically hindered bases such as NaHMDS or
LiTMP allow deprotonation at the carbon atom adjacent to the two boron atoms, affording a $\alpha$-bis(boryl) carbanion. These should therefore be the most promising bases for the development of a difunctionalization process.

Addition of the anion formed on deprotonation of a geminal bis(boron) compound to an ester will yield a bis(boron) enolate which should be able to be trapped by two electrophilic species. However, before the outset of our work, the selectivity of trapping of such bis(boron) enolate species was unknown. We hoped that trapping of the bis(boron) enolate would occur selectively at the position that boron was introduced and lead to exclusive $\alpha, \alpha$-difunctionalization.

Difunctionalization of ketones

Base-mediated enolate formation

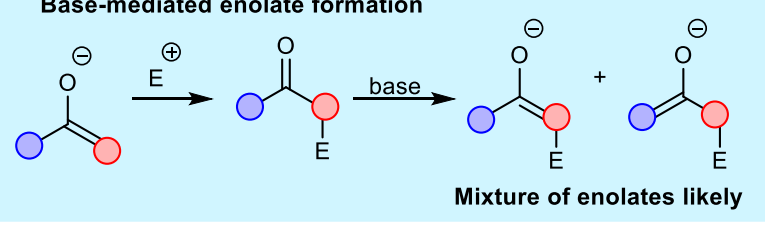

\section{$\alpha$-diazocarbonyl compounds}

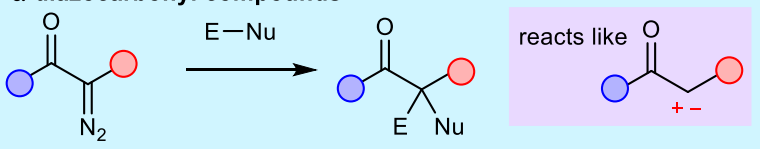

This work: Bis-enolate equivalents

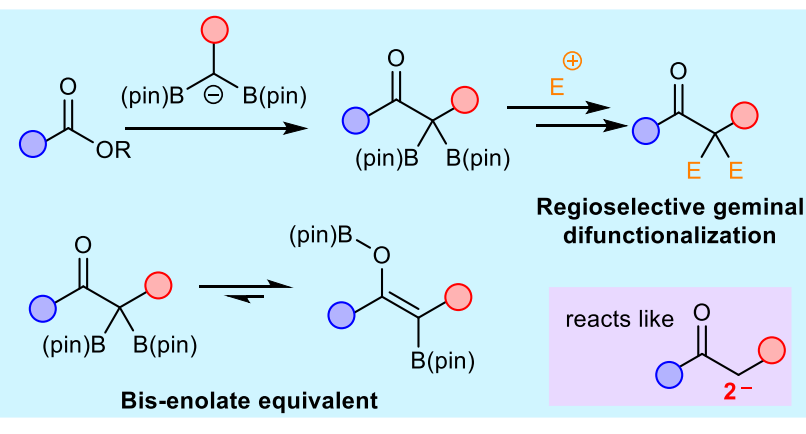

Scheme 3 Approaches to difunctionalization of carbonyl compounds 


\section{Boron enolates by coupling}

We began by investigating whether our bis(boron) enolate, formed on addition of a geminal bis(boron) compound to an ester could be doubly trapped with a range of electrophiles (Scheme 4).11 Our initial investigations were in fluorination, as our laboratory had reported several previous examples of the synthesis and reactivity of fluorinated ketones. ${ }^{12} \alpha$-Fluorination can have profound effects on enolate formation. Fluorination does indeed lower the $\mathrm{pK}_{\mathrm{a}}$ of a carbonyl compound, however, this does not generally lead to an increase in the reactivity of fluorinated enolates. Fluorination lowers the reactivity of an enolate by its electron-withdrawing effect, whilst also destabilizing the change in hybridization from $\mathrm{sp}^{3}$ to $\mathrm{sp}^{2}$ on enolate formation. In general this effect leads to low reactivity of fluorinated enolates. In the case of a non-symmetrical ketone with a fluorinated and non-fluorinated substituent, electrophilic trapping will typically occur on the non-fluorinated side. This makes the synthesis of $\alpha, \alpha$-difluorinated ketones challenging.

Addition of a geminal bis(boron) compound to an ester containing an aromatic substituent proceeded well in the presence of sodium hexamethyldisilazide (NaHMDS) as base to yield the proposed bis(boron) enolate species. This species could then be trapped with NFSI as an electrophilic source of fluorine to yield an $\alpha, \alpha$-difluoroketone. Various useful synthetic handles such as ring halogens and boronic esters for further coupling processes could be tolerated by this reaction. The reaction also proceeded with equal efficiency on a gram-scale.

An alternative choice of base was required when esters containing an aliphatic substituent were used. Although the $\mathrm{pK}_{\mathrm{a}}$ values of geminal bis(boron) compounds have not yet been measured, it would seem that NaHMDS ( $\left.\mathrm{pK}_{\mathrm{a}} 26\right)$ is not sufficient to achieve complete deprotonation of a geminal bis(boron) compound, as side reactions due to Claisen-type condensations of the starting material often compete with the desired reaction when this base is used, even if the base is mixed with the geminal bis(boron) compound for a period before ester addition. Instead, LiTMP ( $\mathrm{pK}_{\mathrm{a}}$ 36) was used to achieve complete initial deprotonation of the geminal bis(boron) compound, before addition of the ester, resulting in a much cleaner reaction. This approach led to clean and selective difluorination, at the position

Fluorination
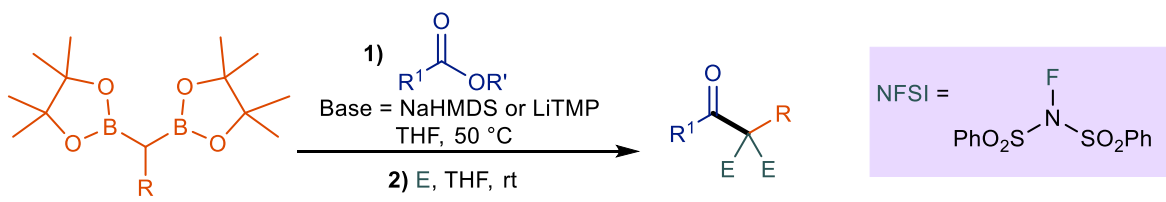

Fluorination

Conditions A

$\mathbf{R}^{1}=$ Aromatic

1. NaHMDS, THF, $50^{\circ} \mathrm{C}$<smiles>[R]OC([R])=O</smiles>

2. NFSI, THF, rt

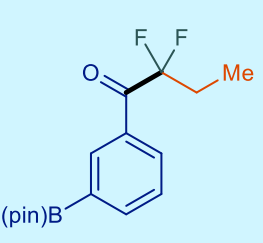

1a, $52 \%$

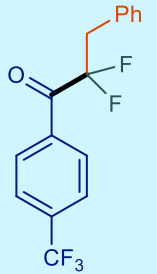

1b, $55 \%$<smiles>C/C=C\CCC(F)(F)C(=O)c1ccc(Cl)nc1</smiles>

1c, $71 \%$

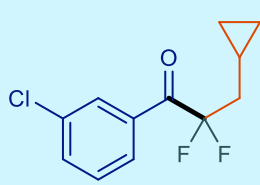

1e, $74 \%$

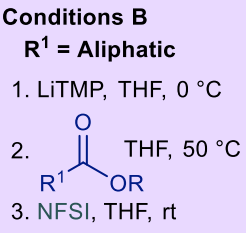

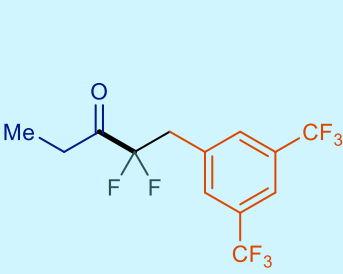

2c, $43 \%$<smiles>CC(F)(F)C(=O)C1CCOCC1</smiles>

2a, $66 \%$<smiles>CCC(F)(F)C(=O)CCc1ccccc1</smiles>

2b, $62 \%$

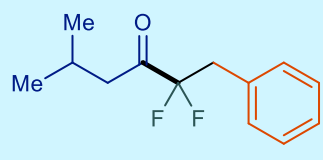

2d, $61 \%$

Methylation

Conditions A

$\mathbf{R}^{1}=$ Aromatic

1. NaHMDS, THF, $50^{\circ} \mathrm{C}$<smiles>[R]OC([R])=O</smiles>

2. Mel, THF, rt<smiles>CC(C)(Cc1ccccc1)C(=O)c1ccc(OCc2ccccc2)cc1</smiles><smiles>CC(C)C(=O)c1ccc(-c2ccccc2)cc1</smiles>

3c, $59 \%$ 3b, $49 \%$

3a, $86 \%$<smiles>CCC(C)(C)C(=O)c1cccc2c1ccn2C</smiles>

3d, $63 \%$

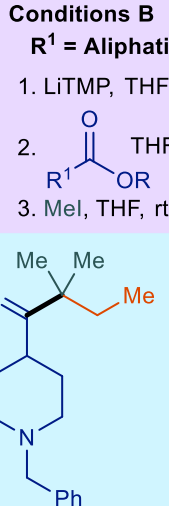

4b, $62 \%$<smiles>COc1ccc(CCC(=O)C(C)(C)Cc2ccc(Cl)cc2)cc1</smiles>

4a, $72 \%$

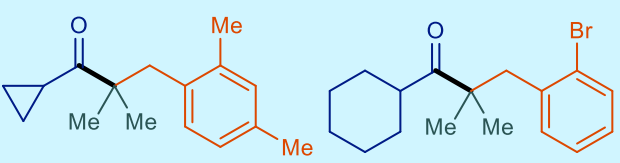

4c, $65 \%$

4d, $61 \%$ 
that boron was introduced by nucleophilic substitution.

The same approach was taken for the development of a geminal dimethylation process. Now iodomethane was used as electrophile. To achieve the highest yields of dimethylation this electrophile was used in a five-fold excess. Again, different bases were required depending on whether an enolizable aliphatic ester (LiTMP) or a non-enolizable aromatic ester (NaHMDS) was used as starting material. In addition, trichloroisocyanuric acid could be used as a chlorinating agent to in a dichlorinative coupling process.

Since the development of this reaction by our research group, other groups have been active in this research area. Almost concurrent to our disclosure, Liu reported an alkylative coupling of carboxylic acids with geminal bis(boron) compounds (Scheme 5). ${ }^{13}$ This reaction used 2.5 equiv. of $\mathrm{MeLi}$ - one equivalent to deprotonate the carboxylic acid and form a carboxylate, and a second to achieve deboronation of the geminal bis(boron) compound and form a $\alpha$-mono(boryl) carbanion. The range of alkylating agents that was compatible with this reaction was broad. $\alpha$-Halo carbonyl compounds, allyl and propargyl halides, as well as primary and secondary halides and Mannich electrophiles are all compatible. It was impressive that a lithium carboxylate was a viable electrophile for this reaction, although elevated reaction temperatures of $100^{\circ} \mathrm{C}$ were needed.

Chirik has also reported an alkylative coupling of esters with geminal bis(boron) compounds (Scheme 5). ${ }^{14}$ This reaction proceeded under much milder conditions. In this case deboronation to form a $\alpha$-mono(boryl) carbanion was promoted by LiOtBu. However, only benzyl-substituted geminal bis(boron) compounds were compatible with this reaction. Impressively, Chirik was able to use geminal bis(boron) compounds bearing two different substituents to prepare ketones containing a quaternary carbon with four different groups attached.

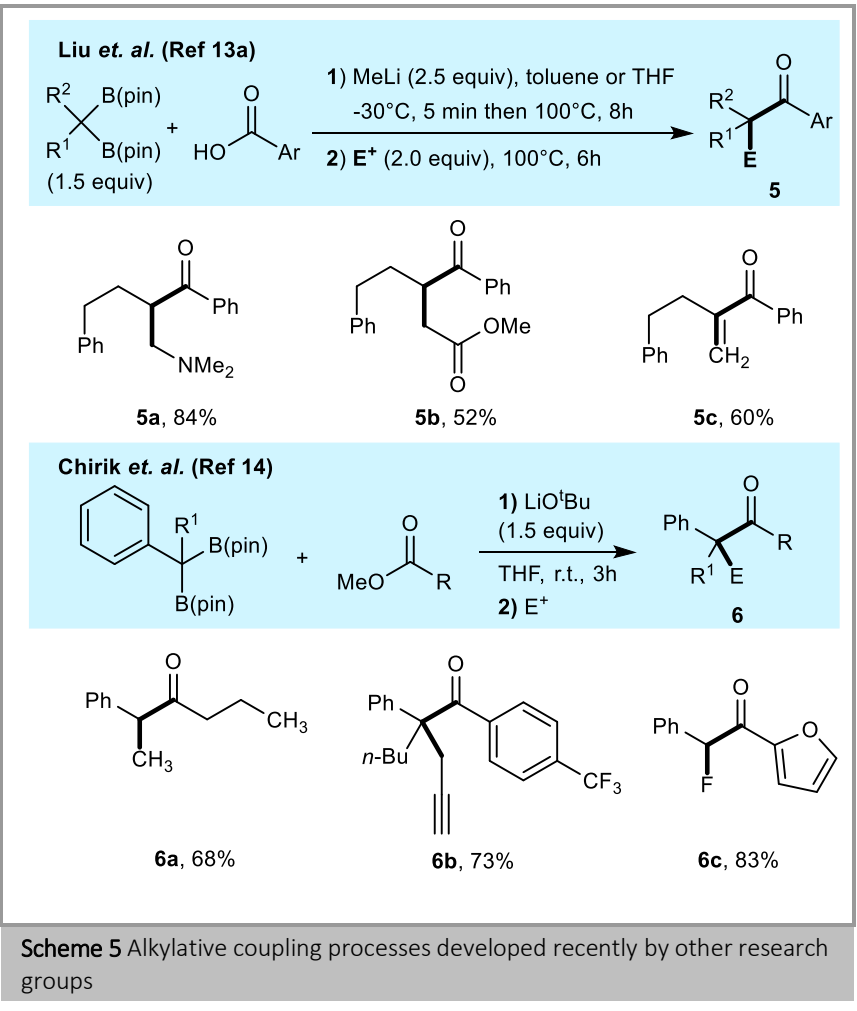

It has also been shown that the boron enolate generated on the addition of a borylated carbanion to a carbonyl compound at the carboxylic acid oxidation level can undergo palladium-catalyzed cross coupling reactions (Scheme 6). Liu's group generated mono(boron) enolates by their addition of geminal bis(boron) compounds to carboxylic acids as described above. ${ }^{13 a}$ These boron enolates could then undergo Pd-catalyzed cross-coupling with a range of aryl bromides. In a similar vein, Xu has generated boron enolates by the nBuLi-promoted addition of geminal bis(boron) compounds to DMF, followed by palladium-catalyzed allylation using allyl acetate derivatives. ${ }^{15}$

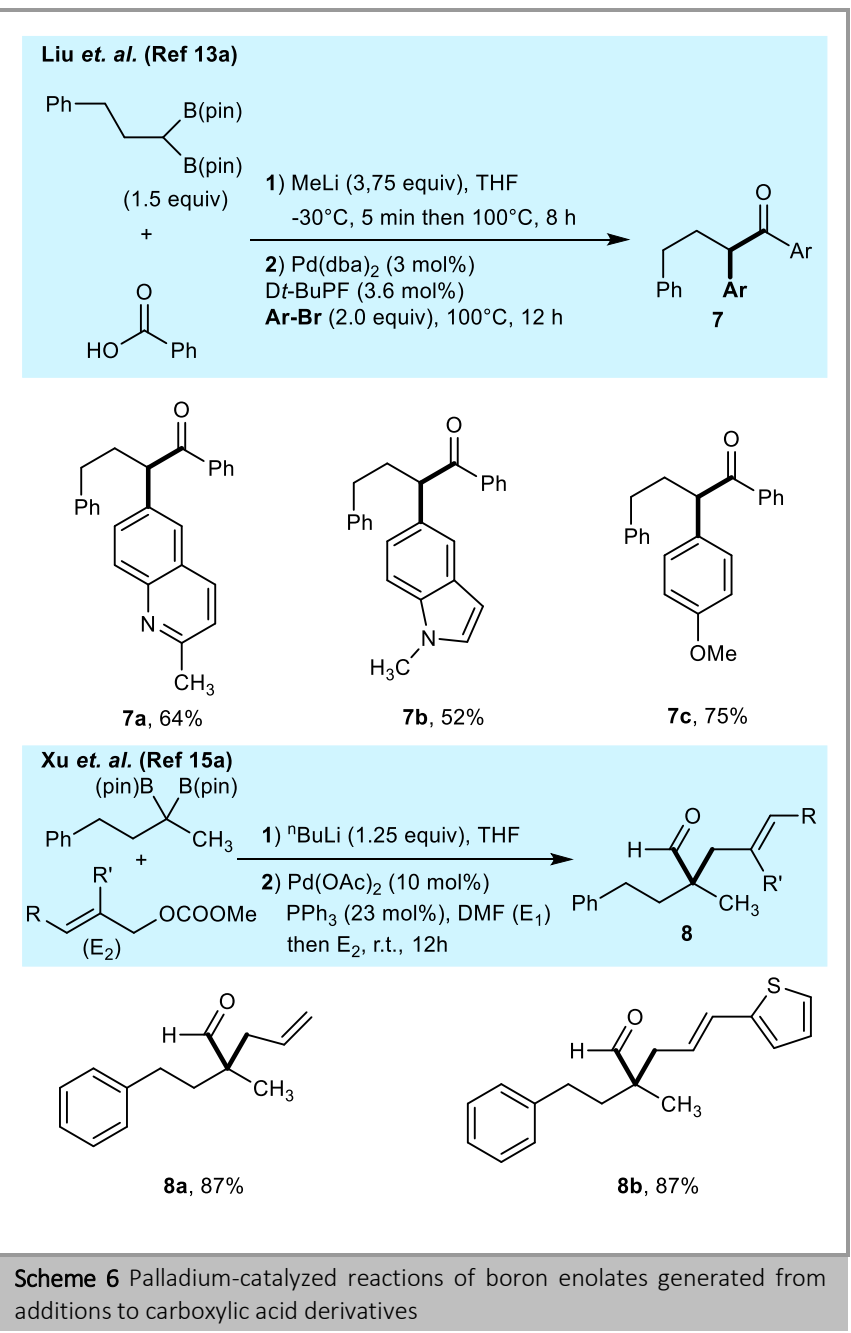

\section{Towards sequential trapping}

It would of course be of interest to be able to perform the electrophilic trapping of bis(boron) enolates with two different electrophiles sequentially. This would allow the synthesis of quaternary carbon centres with four different substituents appended. This would provide a powerful synthetic strategy for the rapid assembly of diversely substituted carbonyl compounds.

Working towards this goal we decided to study the reaction of a bis(boron) enolate intermediate with both iodomethane and benzyl bromide. A bis(boron) enolate was initially formed under our standard conditions by the reaction of bis(pinacolatoboryl)methane with ethyl benzoate in the presence of NaHMDS. Iodomethane (1 equivalent) was then added to the reaction mixture, and after an additional 1 hour of 


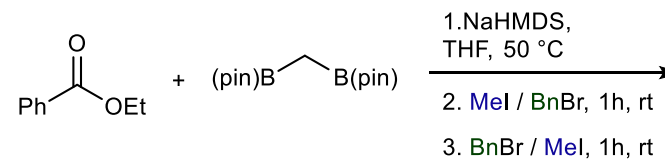

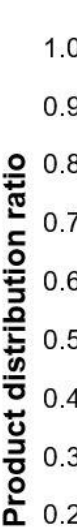

1.0

0.9

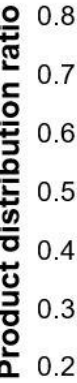

0.1

0.0

RXN A: Sequential addition

1. Mel (1 equiv) $1 \mathrm{hr} 2 . \mathrm{BnBr}(1$ equiv)<smiles>CC(Cc1ccccc1)C(=O)c1ccccc1</smiles>

$10 \mathrm{a}$<smiles>CCC(=O)c1ccccc1</smiles>

$10 \mathrm{~b}$<smiles>CC(C)C(=O)c1ccccc1</smiles><smiles>O=C(c1ccccc1)C(Cc1ccccc1)c1ccccc1</smiles>

$10 c$

$10 d$

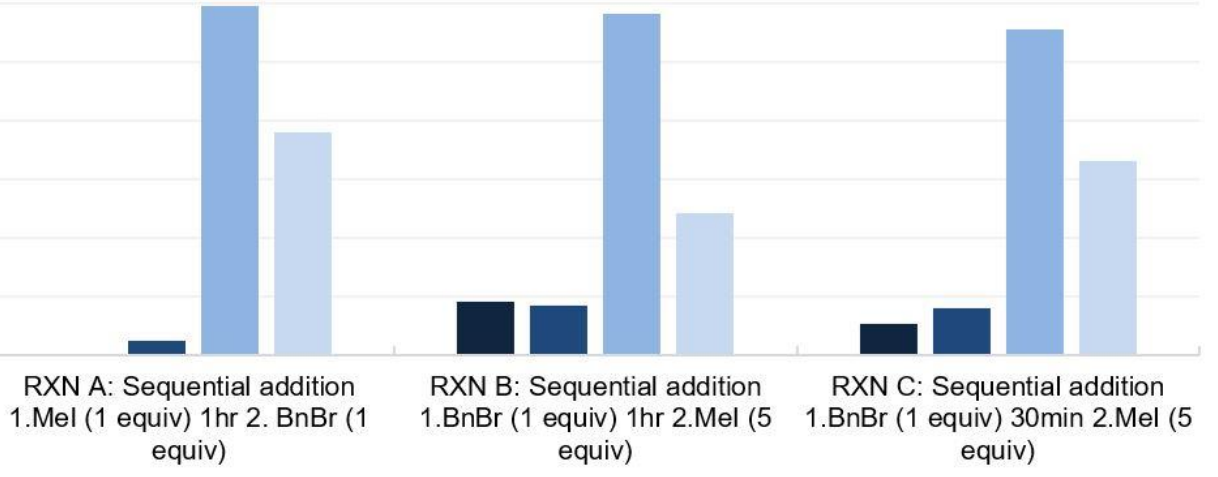

$\because 10 \mathrm{a}=10 \mathrm{~b}=10 \mathrm{c}=10 \mathrm{~d}$

Scheme 7 Attempts towards a sequential coupling process

stirring, benzyl bromide was also added. Experiments in which the order of addition was reversed (benzyl bromide first), and the time between additions was shortened to 30 minutes were also performed.

These experiments (Scheme 7) showed that the desired product 10a of sequential addition (i.e. containing one methyl and one benzyl group) was not formed in more than trace amounts. Instead the product distribution was dominated by products either containing two methyl groups 10c or two benzyl groups 10d. The order of addition of the electrophiles and the time between additions made relatively little difference to this product distribution.

In order to better understand the observed product distribution, we decided to perform a kinetic experiment to examine the growth of different species over time (Scheme 8). After formation of a bis(boron) enolate under our standard conditions, we added 1 equivalent of benzyl bromide at room temperature and took reaction samples at regular intervals over a 30 minute period, quenching each sample immediately with water. We analyzed the reaction mixture by ${ }^{1} \mathrm{H}$ NMR, looking both for the formation of a methyl ketone product $\mathbf{1 1}$ (formed from quenching of unreacted bis(boron) enolate with water on work-up), as well as mono- 12 and di-benzylated $\mathbf{1 3}$ products. This analysis showed a regular decay of the bis(boron) enolate through a decreasing amount of product at all time points was the di-benzylated product 13 . The concentration of mono-benzylated product 12 was always low, even at the start of the reaction.

These results can be explained by considering the relative reactivities of the boron enolate formed on initial substitution of formation of methyl ketone $\mathbf{1 1}$ over time. However, the major

bis(pinacolatoboryl)methane with an ester (14), and the boron enolate formed after reaction of $\mathbf{1 4}$ with one equivalent of an alkylating electrophile (15). It seems likely that the presence of an electron-donating alkyl substituent in $\mathbf{1 5}$ increases its nucleophilicity relative to unsubstituted $\mathbf{1 4}$, ensuring that any additional electrophile in the reaction mixture reacts immediately with substituted enolate $\mathbf{1 5}$, rather than

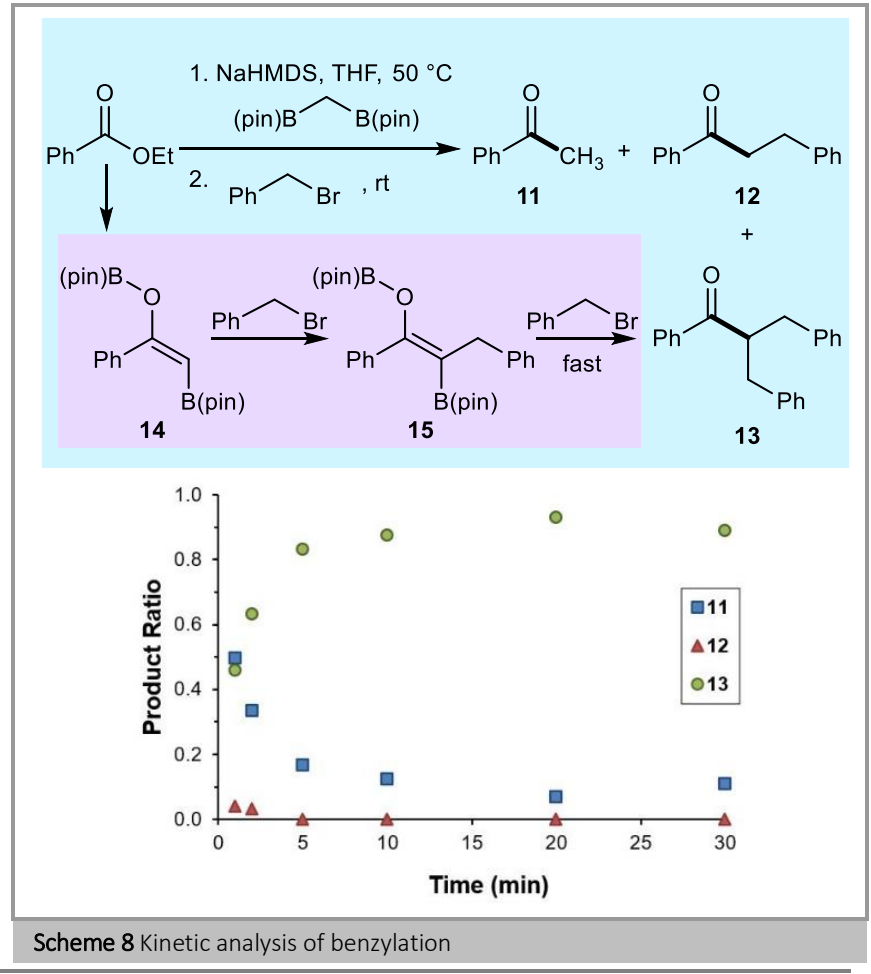


unsubstituted enolate 14. This results in the rapid formation of disubstituted product 13, and ensures that the concentration of monosubstituted enolate $\mathbf{1 5}$ is always low as it immediately reacts with a further equivalent of electrophile. Therefore, little monosubstituted product $\mathbf{1 2}$ is ever observed in the reaction mixture. These results raise questions over the possibility of developing a sequential coupling process through this approach.

\section{Summary and outlook}

The generation of boron enolates triggered by the addition of deprotonated organoboron compounds into esters is proving to be an exciting and viable strategy for the synthesis of functionalized carbonyl compounds. Our work has demonstrated how the addition of deprotonated geminal bis(boron) compounds into esters can generate reactive bis(boron) enolate intermediates which can undergo double-electrophilic trapping with fluorinating agents and alkyl halides. Overall this process represents a difluorinative / dimethylative coupling of esters with geminal bis(boron) compounds.

We have demonstrated challenges in the trapping of the bis(boron) enolates with two different electrophiles which we will target to solve in future work. In addition, the development of novel processes in which boron enolates prepared through this approach undergo a broad range of metal-catalyzed coupling processes to forge new carbon-carbon and carbon-heteroatom bonds are likely to be of great interest for the efficient preparation of novel carbonyl compounds.

\section{Acknowledgment}

We thank the University of Brighton for support and funding.

\section{Biosketches}

\begin{tabular}{|l|l|} 
Dr. Graham Pattison is currently \\
Lecturer in Organic Chemistry at the \\
University of Brighton. He studied \\
for a MChem degree in Chemistry at \\
Durham University and a PhD in \\
heterocyclic organofluorine \\
chemistry at the same institution \\
(Prof. Graham Sandford). He moved \\
to the University of Edinburgh for a \\
postdoctoral position with Prof. Hon \\
Wai Lam, before joining the \\
University of Warwick for an \\
independent research fellowship \\
position. He moved to Brighton in \\
2018, where his research interests \\
are in organofluorine chemistry, \\
organoboron chemistry and in \\
catalysis.
\end{tabular}

\section{References}

(1) d'Angelo, J. Tetrahedron 1976, 32, 2979-2990.

(2) House, H. O.; Kramar, V. J. Org. Chem. 1963, 28, 3362-3379.

(3) (a) He, Z.; Yudin, A. K. J. Am. Chem. Soc. 2011, 133, 13770-13773;

(b) Li, J.; Burke, M. D. J. Am. Chem. Soc. 2011, 133, 13774-13777; (c) He, Z.; Zajdlik, A.; Yudin, A. K. Dalton Transactions 2014, 43, 1143411451; (d) St. Denis, J. D.; He, Z.; Yudin, A. K. ACS Catalysis 2015, 5, 5373-5379; (e) Trinchera, P.; Corless, V. B.; Yudin, A. K. Angew. Chem.
Int. Ed. 2015, 54, 9038-9041; (f) Lv, W.-X.; Zeng, Y.-F.; Li, Q.; Chen, Y.; Tan, D.-H.; Yang, L.; Wang, H. Angew. Chem. Int. Ed. 2016, 55, 1006910073; (g) Corless, V. B.; Holownia, A.; Foy, H.; Mendoza-Sanchez, R.; Adachi, S.; Dudding, T.; Yudin, A. K. Org. Lett. 2018, 20, 5300-5303; (h) Ng, E. W. H.; Low, K.-H.; Chiu, P. J. Am. Chem. Soc. 2018, 140, 35373541; (i) Yang, J.-M.; Zhao, Y.-T.; Li, Z.-Q.; Gu, X.-S.; Zhu, S.-F.; Zhou, Q.L. ACS Catalysis 2018, 8, 7351-7355; (j) Dai, W.; Geib, S. J.; Curran, D. P. J. Am. Chem. Soc. 2019, 141, 12355-12361; (k) Radcliffe, J. E.; Fasano, V.; Adams, R. W.; You, P.; Ingleson, M. J. Chem. Sci. 2019, 10, 1434-1441; (l) Ren, S.-C.; Zhang, F.-L.; Xu, A.-Q.; Yang, Y.; Zheng, M.; Zhou, X.; Fu, Y.; Wang, Y.-F. Nature Commun. 2019, 10, 1934; (m) Ivon, Y. M.; Kuchkovska, Y. O.; Voitenko, Z. V.; Grygorenko, O. O. Eur. J. Org. Chem. 2020, doi.org/10.1002/ejoc.202000078

(4) (a) Matteson, D. S.; Moody, R. J. J. Am. Chem. Soc. 1977, 99, 31963197; (b) Matteson, D. S.; Arne, K. J. Am. Chem. Soc. 1978, 100, 13251326; (c) Matteson, D. S.; Moody, R. J. Organometallics 1982, 1, 20-28; (d) Matteson, D. S.; Majumdar, D. Organometallics 1983, 2, 230-236. (5) Mukaiyama, T.; Murakami, M.; Oriyama, T.; Yamaguchi, M. Chem. Lett. 1981, 10, 1193-1196.

(6) (a) Matteson, D. S.; Moody, R. J.; Jesthi, P. K. J. Am. Chem. Soc. 1975, 97, 5608-5609; (b) Matteson, D. S.; Moody, R. J. J. Org. Chem. 1980, 45, 1091-1095; (c) Endo, K.; Hirokami, M.; Shibata, T. J. Org. Chem. 2010, 75, 3469 - 3472; (d) Coombs, J. R.; Zhang, L.; Morken, J. P. Org. Lett. 2015, 17, 1708-1711; (e) Namirembe, S.; Gao, C.; Wexler, R. P.; Morken, J. P. Org. Lett. 2019, 21, 4392-4394.

(7) Stephens, T. C.; Pattison, G. Org. Lett. 2017, 19, 3498-3501.

(8) (a) Tao, J.; Tran, R.; Murphy, G. K. J. Am. Chem. Soc. 2013, 135, 16312-16315; (b) Emer, E.; Twilton, J.; Tredwell, M.; Calderwood, S.; Collier, T. L.; Liégault, B.; Taillefer, M.; Gouverneur, V. Org. Lett. 2014, 16, 6004-6007; (c) Coffey, K. E.; Murphy, G. K. Synlett 2015, 26, 10031007; (d) Yuan, W.; Eriksson, L.; Szabó, K. J. Angew. Chem. Int. Ed. 2016, 55, 8410-8415; (e) Huang, J.; Li, L.; Chen, H.; Xiao, T.; He, Y.; Zhou, L. Org. Chem. Front. 2017, 4, 529-533.

(9) Fustier-Boutignon, M.; Nebra, N.; Mézailles, N. Chem. Rev. 2019, $119,8555-8700$.

(10) (a) Miralles, N.; Maza, R. J.; Fernández, E. Adv. Synth. Catal. 2018, 360, 1306-1327; (b) Nallagonda, R.; Padala, K.; Masarwa, A. Org. Biomol. Chem. 2018, 16, 1050-1064; (c) Wu, C.; Wang, J. Tetrahedron Lett. 2018, 59, 2128-2140.

(11) Iacono, C. E.; Stephens, T. C.; Rajan, T. S.; Pattison, G. J. Am. Chem. Soc. 2018, 140, 2036-2040.

(12) (a) Nash, T. J.; Pattison, G. Eur. J. Org. Chem. 2015, 3779-3786; (b) Dobson, L. S.; Pattison, G. Chem. Commun. 2016, 52, 11116-11119; (c) Leng, D. J.; Black, C. M.; Pattison, G. Org. Biomol. Chem. 2016, 14, 1531-1535; (d) Pattison, G. Beilstein J. Org. Chem. 2017, 13, 29152921; (e) Pattison, G. Eur. J. Org. Chem. 2018, 2018, 3520-3540; (f) Pattison, G. Org. Biomol. Chem. 2019, 17, 5651-5660.

(13) (a) Sun, W.; Wang, L.; Xia, C.; Liu, C. Angew. Chem. Int. Ed. 2018, 57, 5501-5505; (b) Hu, Y.; Sun, W.; Liu, C. Synlett 2019, 30, 11051110; (c) Zou, L.-H.; Fan, M.; Wang, L.; Liu, C. Chin. Chem. Lett. 2019. (14) Lee, B.; Chirik, P. J. J. Am. Chem. Soc. 2020, 142, 2429-2437. (15) (a) Zheng, P.; Zhai, Y.; Zhao, X.; Xu, T. Chem. Commun. 2018, 54, 13375-13378; (b) Zheng, P.; Zhai, Y.; Zhao, X.; Xu, T. Org. Lett. 2019, 21, 393-396. 